\title{
HAS SOCIAL SECURITY INFLUENCED FAMILY FORMATION AND FERTILITY IN OECD COUNTRIES? AN ECONOMIC AND ECONOMETRIC ANALYSIS
}

\author{
Isaac Ehrlich \\ Jinyoung Kim \\ Working Paper 12869 \\ http://www.nber.org/papers/w12869
NATIONAL BUREAU OF ECONOMIC RESEARCH
1050 Massachusetts Avenue
Cambridge, MA 02138 \\ January 2007
}

The views expressed herein are those of the author(s) and do not necessarily reflect the views of the National Bureau of Economic Research.

(C) 2007 by Isaac Ehrlich and Jinyoung Kim. All rights reserved. Short sections of text, not to exceed two paragraphs, may be quoted without explicit permission provided that full credit, including $\odot$ notice, is given to the source. 
Has Social Security Influenced Family Formation and Fertility in OECD Countries? An Economic and Econometric Analysis

Isaac Ehrlich and Jinyoung Kim

NBER Working Paper No. 12869

January 2007

JEL No. J1,O1

\begin{abstract}
There is growing concern about a decline in the total fertility rate worldwide, but nowhere is the concern greater than in OECD countries, some of which already face the prospect of population decline as well. While the trend is largely the result of structural economic and social changes, our paper indicates that it is partly influenced by the scale of the defined-benefits, pay-as-you-go (PAYG) social security systems operating in most countries. Through a dynamic, overlapping-generations model where the generations are linked by parental altruism, we show analytically that social security tax and benefit rates generate incentives for individuals to reduce not just the fertility rate within families, but also the incentive to form families, which we capture empirically by the fraction of adults married. We conduct calibrated simulations as well as regression analyses that measure the quantitative importance of social security tax rates in lowering both net marriage and total fertility rates. Our results show that the impact of social security on these variables has been non-trivial. Our calibrated simulations also enable us to study the effects of changes in the structure of social security on family formation and fertility.
\end{abstract}

Isaac Ehrlich

415 Fronczak Hall

University of Buffalo

Box 601520

Buffalo, NY 14260-1520

and NBER

mgtehrl@buffalo.edu

Jinyoung Kim

Department of Economics

Korea University

5-1, Anam-Dong, Sungbuk-Ku

Seoul, Korea 136-701

jinykim@korea.ac.kr 


\section{Introduction}

Economists and public-policy makers have been increasingly concerned about the growing financial vulnerability of defined-benefits, pay-as-you-go (PAYG) pension systems. In the US, the 2006 report of the Social Security Administration projects that from 2000 to 2050 the old-age dependency ratio (population in ages 65 and over relative to 20-64) will rise from 20.8 in 2000 to 38.0 in 2050 and that the OASDI expenditures as a share of GDP will rise from $4.15 \%$ to 6.26\%. Comparable statistics for the 15 EU countries show a considerably larger financial vulnerability, with the old-age dependency ratio rising from 28.3 in 2000 to 55.9 in 2050 and the Public Pension Expenditures share of GDP rising from 10.4\% in 2000 to $13.3 \%$ in 2050 - double of that in the US. (See CEC, 2000, and EPC, 2001.) Our concern in this paper, however, goes much beyond the projected increases in the systems' financial vulnerability. We focus here on unintended demographic and economic consequences arising from the specific structure of the PAYG system, which is common to all OECD countries.

Data from 57 countries show that average annual marriage net of divorce rate per 1000 people age 15 and over fell from 9.72 in 1960 to 6.40 in 1990, and that average total fertility rate (TFR) fell from 3.82 in 1965 to 2.07 in 1989. In OECD countries the marriage net of divorce rate fell even more significantly from 9.97 in 1960 to 4.86 in 1990, and TFR fell from 2.80 in 1965 to 1.74 in 1989. These dramatic trends stem from secular trends in basic determinants of family formation and fertility worldwide. Our theoretical and empirical analyses indicate, however, that the PAYG social security system operating in most countries have independently contributed to these trends, and thus, ironically, to the system's growing financial vulnerability.

More specifically, controlling for a number of theoretically relevant variables that affect the incentive to form families and bear children in a panel of 28 OECD countries (see Table 2) over the 
period 1960-1992, we find that higher ratios of social security's pension benefits to GDP, which approximates the PAYG system's equilibrium tax rate (PEN), have depressed the rate of marriage net of divorce - decreasing marriage and increasing divorce - and the total fertility rate. These effects are stronger in OECD countries relative to other countries in our sample, and they are generally not observed in countries where social security is a defined-contribution, fully funded provident fund, rather than an unfunded, defined-benefits PAYG system.

The theoretical insights we offer to rationalize these effects are based on a model of endogenous growth where human capital is the engine of growth, family choices include fertility and investment in children's education (quantity and "quality" of children) by altruistic parents, and family formation itself is a choice variable. Theoretically, we focus on the way the scale of the PAYG system, as represented by equilibrium tax and spending rates, affects these decisions.

The possible effects of PAYG systems on fertility, typically measured by the total fertility rate (TFR), were analyzed in several previous studies as well. ${ }^{1}$ All implicitly reach a common conclusion, however, which is a central proposition in Ehrlich and Lui (1998): exogenous increases in PAYG taxes must exert opposite effects on at least one of the parental choice variables. We go beyond all previous studies by considering the role of net family formation, since families are more likely to bear children than single households. Consideration of family formation adds to our understanding of the way social security taxes affect TFR, since changes in the latter may come about in principle from changes in the percentage of families among all households, as well as from changes in the within-families fertility rate (FFR).

Second, we develop our inferences using an "endogenous growth" model which allows for an economy's long-term, self-sustaining productivity growth due to human capital accumulation. This dynamic framework enables us to assess the impact of social security taxes at any given stage 
of development, as well as over a "demographic transition" phase of development, which typically follows an economy's takeoff from a low development stage of stagnation to a perpetual-growth regime, and which our model accounts for as well. We can thus study the possible effects of social security on demographic variables in a panel of countries that are in different stages of development.

We assess the quantitative impact of exogenous increases in proportional payroll taxes via both a calibrated simulation analysis using OECD data, and a regression analysis in which we implement our model using OECD and international panel data. Our findings from these two estimation methods corroborate one another. Although theoretically we treat social security taxes as an exogenous policy variable, empirically we allow for their possible endogeneity as well.

We find that higher tax rates may have generated significant reductions in our key demographic variables. For example, our calibrated simulations using OECD data suggest that social security taxes may account for $48.1 \%$ of the fall in TFR in OECD countries between 1965 and 1989. By comparison, similar simulations with US data (see Ehrlich and Kim, 2006) report that social security taxes account for $26.8 \%$ of the fall in TFR in the US between 1950 and 2000 .

\section{The Analytical Framework}

\section{How a Defined-Benefits, PAYG System Works}

There are two basic insurance structures that social security systems, and even employerbased pension programs, have adopted to provide old-age benefits to workers: definedcontributions and defined-benefits plans.

Defined-contributions plans work like pension contracts offered by the insurance industry: individuals purchase future annuity benefits by making premium contributions - much like the way they purchase life insurance - and their individual accounts are credited for the amounts contributed. The ultimate pension benefits depend on the actuarial value of the returns 
these contributions yield through investments in alternative investment vehicles. Such systems may be managed by governments, as in Singapore, or by a regulated private insurance system, as in many South American countries, where competing pension providers offer workers a choice of investments in alternative portfolios of government bonds and private capital assets.

Defined-benefits, PAYG systems which are common to all OECD countries, operate very differently. The essence of the PAYG setup is that payments to retirees are supported by payroll taxes applied to the next generation of workers. The benefits are "defined", set by the political system in a largely uniform way: there is only a loose connection between the benefits one receives and the amounts one actually contributes over the labor career. And although total benefits to retirees must ultimately be balanced by the total contributions coming from their children's generation, the personal benefits to recipients do not depend at all on what their own children contribute, or even whether they have any children.

The PAYG system can thus induce unintended consequences. Since defined benefits are independent of contributions made by children, parents are not compensated individually for raising more or better-educated children. As a result, PAYG payroll taxes induce behavior that is not socially optimal: They diminish the incentive of individual workers to bear and invest in children, save for retirement, or generally form families altogether, because they lower the private rewards from family investments relative to alternative individual pursuits. These insights are backed up more rigorously in the following sections.

\section{The Benchmark Model}

A formal outline of our benchmark model is offered in Appendix 1 (see also our NBER paper). Here we offer a general discussion of the model, which sets the stage for the simulation and regression analyses we report in section I.4 and part II of this paper. 
The model recognizes the interaction among three overlapping generations: dependent children, working young adults, and retired old adults. All household choices, including marriage, children, and savings are thus made by the young adults aiming to maximize lifetime welfare. Production per worker in the economy in time $t$ is determined essentially by the level of human capital possessed by each worker (for analytical simplicity all workers are assumed to be homogeneous), $\mathrm{H}_{\mathrm{t}}$. In a steady state, there is a proportional relationship between a worker's production capacity, or per-capita income, and human capital per worker, so productivity growth comes strictly from the human capital possessed by the next generation of workers in time $t+1$, $\mathrm{H}_{t+1}$, relative to that of their parents' generation, $\mathrm{H}_{t}$ in time $t$ (see equation A.1). The rationale is that human capital - information and knowledge - is the only asset in the economy that is not subject to diminishing returns, as Frank Knight argued more than a half century ago. ${ }^{2}$

Human capital accumulation, in turn, is determined by the willingness of the current generation of adults who form families to invest a fraction of their production capacity, $\mathrm{h}_{\mathrm{t}}$, in the knowledge of the future generation - their offspring. Parents are motivated essentially by altruism toward their children (formally, the altruism function is specified by $\mathrm{C}_{\mathrm{j} 3}$ in equation A.7), but since family resources are always limited, a parent's decisions include a choice of both the number of children she wishes to bear and raise, $\mathrm{n}_{\mathrm{t}}$, and her rate of investment in human capital per child, $\mathrm{h}_{\mathrm{t}}$, as a fraction of production capacity. This intergenerational link is critical, because if each generation acted in isolation of all past and future generations, all generations would just replicate the level of human capital they can attain and no growth would be possible.

A few logical ramifications arise form this formulation:

A. Family formation. Since most children are born in traditional families, a critical determinant of fertility and population growth is the proportion of married adults, $\mathrm{p}_{\mathrm{t}}{ }^{3}$ 
Movements in this variable are then controlled largely by "net marriage", or the rate of marriage net of divorce. These determinants are thus treated as distinct choice variables in our model. We offer a probabilistic model of search for a marriage mate that takes into account the costs and benefits of finding a mate and enjoying the superior psychic utility of having a family and children $\left(\mathrm{V}_{\mathrm{m}}\right)$, as opposed to staying single $\left(\mathrm{V}_{\mathrm{s}}\right)$. In this framework, the equilibrium probability of marriage, or the fraction of married adults, $\mathrm{p}_{\mathrm{t}}$ becomes a choice variable, which is motivated by the net welfare gain from forming a family $\left[\mathrm{V}_{\mathrm{m}}-\mathrm{V}_{\mathrm{s}}\right]$. As we show below, social security taxes and benefits can influence this choice.

B. Substitutability of quantity and quality of children. Since children consume a significant fraction of earning capacity, for those forming a family a critical choice becomes a possible tradeoff between the quantity of children per parent (n), and investment in the human capital of each child (h). Indeed, our model indicates that these two variables tend to be "substitutes" in connection with changes of the implicit unit cost of each. This result is significant for understanding the opposing movements in these variables over the development process: economies that take off from a low income, stagnant equilibrium into persistent growth regimes typically experience continuous accumulation of human capital along with declining total fertility rates - a phenomenon known as the "demographic transition". Our model generates this feature of the development process analytically - for both family formation and family fertility rate - so the implications we derive concerning the effect of social security on these variables are independent of the secular trend produced by the demographic transition.

C. The inefficiency implicit in defined-benefits, PAYG systems. For this system to be in balance, expected benefits per surviving old adult must equal the expected contributions obtained from the number of surviving adult workers per beneficiary, or the "Worker Support Ratio" 
(WSR), which depends on the total fertility rate, TFR=2pn, and which is the product of the proportion of married adults (p) and the family (two-parent) fertility rate (2n). Given the tax rate on earnings $(\theta)$ and the earnings per adult worker, the higher TFR, the higher would be the equilibrium benefits per surviving old adult (see equation A.8). It follows that any reduction in TFR would ultimately lower the equilibrium defined benefits per surviving old adult the PAYG can sustain, $\mathrm{S}_{\mathrm{t}+1}$, at any given tax rate $(\theta)$ and earnings per worker.

This is not the case for any individual household, single or married. If an individual parent has a lower rate of fertility, that parent's social security benefit is not affected, because the latter depends on the average TFR in the population, and thus on aggregate behavior, not on the fertility rate of any individual household. Similarly, if a household is comprised of a single, childless adult, that person's old-age benefits are "defined" (fixed) by the system at the same level as the benefits of a married parent with many children, even though equilibrium defined benefits in the aggregate do depend on the average fertility rate in the aggregate population. This creates an inconsistency between the consequences from fertility choices faced by individual households as opposed to the social security system as a whole, which is inefficient socially as it can distort socially-optimal fertility and family formation decisions as well.

\section{Testable Propositions}

In our benchmark model, we abstract from any inter-temporal or intergenerational resources allocation within households, assuming that social security provides the only means of financing old-age consumption. In this case, an exogenous rise in the scale of social security, represented by a higher equilibrium (balanced-budget) tax rate on earnings, $\theta$, would:

A. unambiguously lower the equilibrium quantity of children per married parents, $\mathrm{n}_{\mathrm{t}}$ (the family fertility rate), leaving unchanged parental investments in the human capital of each child, $\mathrm{h}_{\mathrm{t}}$. This 
proposition implies that any increase in the social security tax lowers the entire dynamic paths of fertility over the demographic transition: it affects both developing and highly developed countries, although not necessarily by the same extent;

B. unambiguously lower the equilibrium fraction of married adults in the population.

The rationale of proposition $\mathrm{A}$ is that for young parents who must spend considerable resources on raising and educating children, a higher balanced-budget tax rate on earnings lowers their ability to consume at young, relative to old age. Technically, the psychic rate of return to young parents from investing in quantity and quality of children becomes lower than the marginal rate of substitution in consumption between young and old age, which generates an incentive to lower spending on children. In principle, both fertility and human capital investment (n and h) may need to fall as a result, but since these two variables are "substitutes", and given our operational definition of altruism (see equation A.7), altruistic parents reduce just fertility without altering their investment in the human capital of each child.

The rationale for proposition B is similar: an increase in the proportional tax rate imposes a higher burden on married household who spend resources on raising and educating children, which single households are entirely exempt from. This, in turn, lowers the net welfare gain from searching for a mate and being married relative to staying single.

\section{Assessing the Quantitative Implications of the Model via Calibrated Simulations}

How important quantitatively are these propositions? One way to measure quantitative significance is to solve the model explicitly through numerical simulations that are calibrated by the observed values of the model's basic parameters, e.g., the average total fertility rate or GDP per-capita over our sample period, or by applying the optimality conditions of the model to infer 
the "missing" values of parameters for which no accurate data exist. The specific numerical values assigned are detailed in Appendix 2.

The calibrated simulations enable us to solve for the basic choice variables of the model: $\mathrm{p}_{\mathrm{t}}, \mathrm{n}_{\mathrm{t}}$, and thus the total fertility rate, $2 \mathrm{p}_{\mathrm{t}} \mathrm{n}_{\mathrm{t}}$, under different assumed values of the tax rates on social security, $\theta$. Such simulations can be done over the entire demographic transition period, but to save space we illustrate the results obtained at the growth equilibrium steady state, which is more applicable to economies in advanced stages of development, such as OECD countries.

Figure 1 plots the simulated solutions for the three demographic variables of our model as functions of autonomous variations in equilibrium social security tax rates, ranging from 0 to $12 \%$ of GDP. The corresponding values of our demographic variables range from .69 to .43 for the proportion of married adults (p); from 2.15 to 1.84 for the number of children per parent (n), and from 2.95 to 1.55 children for TFR. From Figure 1 we can also calculate how much of the actual change in TFR can be explained by the effect of the increased social security tax rate. (We cannot do the same calculation for $\mathrm{p}$ because data on the variable are not consistently reported.) The average TFR in OECD countries fell from 2.8 in 1965 to 1.74 in 1989. During this period, our estimated $\theta$ rose from $3.78 \%$ to $7.49 \%$. Our simulations ascribe $48.1 \%$ of the actually observed change in TFR to the partial effect of the rise in $\theta$ from 1965 to $1989 .{ }^{4}$

Our simulations also indicate that the elasticities of the individually controlled demographic variables $(\mathrm{p}, \mathrm{n}$, and $\mathrm{TFR}=2 \mathrm{pn})$ with respect to a change in the tax rate, $\theta$, get larger at higher values of $\theta$, i.e., a one percent rise in the tax rate causes larger percentage declines in the probabilities of marriage and fertility as the tax level rises. This is essentially because under a concave utility function, the marginal tax burden on parents, as opposed to singles, increases as the tax level rises. The same pattern of results is found over the transitional development stage as 
the economy advances toward a steady state of growth. The implication is that increases in the scale of social security, as measured by $\theta$, are expected to exert a more detrimental effect on family formation and fertility in the more advanced OECD countries relative to less developed economies. This implication, as well as the quantitative results obtained from our simulations concerning the effect of social security taxes on demographic variables, will also be tested empirically via our regression analysis.

\section{Regression Analysis}

We test our basic propositions against international panel data via a reduced-form specification of our model in which the dependent variables are the endogenous demographic variables, and the regressors measure basic parameters, including the social security tax rate, $\theta$. Although $\theta$ is an exogenous variable in our model, we allow for its possible endogeneity in our regression analysis. For variable definitions and sample statistics, see Appendix 3.

\section{The Sample and Variable Construction}

Our social security data are taken from The Cost of Social Security, published by the International Labour Office (ILO). Data are available in 57 countries over 33 years, 1960-1992, but in some countries not for all years. We focus mainly on the subset of the data that includes OECD countries. We compute the theoretical social security tax rate as PEN: the pension portion of social security benefits relative to GDP, representing aggregate earning capacity. Under a balanced budget, expected benefits per surviving old recipient $\pi_{2} \mathrm{~S}_{\mathrm{t}+1}$ must equal expected payroll taxes collected from a surviving young worker $\mathrm{Q}_{\mathrm{t}+1} \equiv \theta\left[\mathrm{p}_{\mathrm{t}} \pi_{1} \mathrm{n}_{\mathrm{t}}\left(\overline{\mathrm{H}}+\mathrm{H}_{\mathrm{t}+1}\right)\right]$ (see equation A.8). Thus, our empirical tax measure PEN $\equiv \pi_{2} \mathrm{~S}_{\mathrm{t}+1} / \mathrm{Q}_{\mathrm{t}+1}=\theta$ consistently measures the equilibrium social security tax rate in our model. 
We use the population's annual marriage net of divorce rate (NETMARRY) as a flow counterpart of our family formation (stock) measure (p). Although we do not model divorce separately, we decompose NETMARRY into a separate MARRY and DIVORCE regressions. We use the official total fertility rate (TFR) as a proxy for average population fertility (2pn).

Our basic explanatory variables include PEN and measures of the survival probabilities to adulthood and to old age, Pi1 and Pi2, (see Appendix 3). Our analysis predicts that both variables generally increase the incentive to form families and to have children, although a higher Pil can also lower fertility (crude birth rates) within families, since parents do not need to compensate for the risk of non-survival of newborn children to adulthood. Since our sample includes a combination of developing and advanced economies, we control for an economy's development stage along the transitional dynamic phase by including per-capita GDP (GDPN) as an endogenous regressor, since our model simulations predicts that over the transitional development phase, both family formation and fertility would be declining as part of the demographic transition. We also include in all regressions the GDP share of government spending $(\mathrm{G})$ to separate the effect of our social security tax from other government taxes and benefits. While we do not have direct measures of the opportunity costs of bearing children (v), we use female labor force participation rate (FLFP) as a proxy for the major component of the opportunity costs of raising children, as well as an indicator of females' financial independence. Data sources are listed in Appendix 3.

\section{Model Specification}

Our basic regression specification is a linear model with country-specific fixed-effects:

(1) $\mathrm{L} \overline{\mathrm{y}}_{\mathrm{t}, \mathrm{t}+4}=\beta_{0}+\beta_{1} \mathrm{PEN}_{\mathrm{t}}+\beta_{2} \mathrm{LPi} 1_{\mathrm{t}}+\beta_{3} \mathrm{LPi} 2_{\mathrm{t}}+\beta_{4} \mathrm{X}_{\mathrm{t}}+\mathrm{u}_{\mathrm{t}}$,

where $\bar{y}_{t, t+4}$ measures the average value of each of our four endogenous variables over overlapping 5-year lead periods, from $t$ to $t+4$; $L$ denotes natural logs; and $\beta_{0}$ is a vector of 
country-specific dummy variables. The vector $\left(X_{t}\right)$ includes $G_{D P N}, G_{t}$ and proxies of other relevant model parameters.

The basic idea is to treat the mean realized values of the model's endogenous variables over periods of intermediate length as samples of their equilibrium values along the transition path to a growth steady state, and to test the effects of initial-period changes in our measure of $\theta$, PEN, on these values (see also Barro and Lee, 2003). The overlapping 5-year lead-period specification in equation (1) is chosen to guarantee a large enough sample size, but we have also experimented with 3 and 7 lead-year specifications, which yield similar quantitative results, and with non-overlapping 5-year periods (see section IV.4). The country dummies in equation (1) control for missing country-specific institutional factors that affect family formation, fertility, and other determinants of population dynamics. ${ }^{5}$ This fixed-effects specification captures within-country variations in all regressors.

Although in equation (1) $\mathrm{PEN}_{\mathrm{t}}$ is entered as a predetermined regressor, empirically it may be endogenous to our model. This is because equilibrium social security tax rates are set by the political system, which is influenced by autonomous movements in the demographic variables $\mathrm{p}$ and $n$, or the population age structure, which affect voters' interests. Furthermore, $\mathrm{GDPN}_{\mathrm{t}}$ is in principle an endogenous variable in our model, since it is determined by human capital accumulation. To account for the possible endogeneity of both GDPN $\mathrm{t}_{t}$ and $\mathrm{PEN}_{\mathrm{t}}$ we also employ a 2 SLS regression analysis (see section IV.1). ${ }^{6}$

As part of our sensitivity analysis, we introduce PEN in both linear and logarithmic forms. A Box-Cox optimal transformation analysis generally favors a linear transformation of PEN, and a log transformation for all other variables in equation (1). Although we report only the results of optimal transformations, alternative transformations of PEN yield similar elasticity estimates. 


\section{Empirical Findings}

Table 1 summarizes the estimated effects of our social security tax measure, PEN, on the basic variables of our model. The dependent variables are the logarithms of the annual rates of the total fertility rate (LTFR), net marriage in the population age 15 and over (LNETMARRY), as well as its corresponding determinants - the rates of marriage and divorce (LMARRY, LDIVORCE) - over a 5-year lead period. For each regression, the first two rows report the estimated regression coefficients $(\beta)$, the ratios of these to their estimated standard deviation (an indication of asymptotic statistical significance) associated with each regressor. For PEN the third row reports the estimated elasticity, calculated at the sample mean.

The basic regression specification is (1), with all variables entered in logs except PEN. (For this reason, the estimated elasticities associated with PEN in Table 1 are computed only at the mid-sample.) Model (column) 1 presents OLS estimates of the effects of the key regressors in equation (1). In the case of family formation regressions, model 2 extends model 1 by adding the deviation of the female/male ratio from $50 \%$ (DSEX) as well as the female labor force participation rate (FLFP) and female-male ratio of schooling years (FSCH). We include these variables as additional regressors since, as the marriage literature indicates, a higher DSEX and FLFP tend to lower the likelihood of finding a mate or having a stable marriage, while FSCH raises it. In the OLS regressions concerning TFR, model 2 includes the latter two regressors as well, since a stable marriage also increases on the margin the family fertility rate, but we also add NETMARRY, rather than DSEX, as an additional regressor (see the reasoning below).

In all regressions, the effect of PEN on the dependent variables is consistent with our theoretical predictions: in all cases, a higher tax rate lowers both our measures of family formation and fertility, and the estimated coefficients appear to be statistically significant with no 
exception, and in all regression models. The estimated effects of all other regressors are also generally consistent with our model predictions.

\section{Social Security Effects on Family Formation}

The measured PEN effects on the net marriage rate in the population 15 and over are significant and consistent with our predictions, despite the limitation of NETMARRY as a flow measure of the fraction of married adults in the population, $p$, which is the relevant theoretical variable in our model. Moreover, while a higher PEN reduces marriage, it raises divorce, as would be expected from the logic of our model, since marriage and divorce have opposite effect on $\mathrm{p}$. Indeed, PEN has a more pronounced effect on NETMARRY than on MARRY, despite the fact that a non-working spouse can have an incentive to marry and stay married, at least over a prescribed number of years, especially when a non-working spouse is legally entitled to collect pension benefits vested with the working spouse. The estimated effect of PEN is also found to be distinct from the generally negative impact of the economy's per-capita income level, GDPN, reflecting our predicted behavior of $\mathrm{p}$ over the transitional development phase.

\section{Social Security Effects on Fertility}

The dependent variable, TFR, stands for the average number of children born to all females age 15-49, averaged over a 5-year lead period. In model 1 the estimated regression coefficients therefore measure the quantitative impact of PEN and the other regressors on both the average fertility rate in the population, which is, in principle, a product of the share of the population married ( $p$ ) and the number of children per family, or the family fertility rate ( $F F R=2 n)$. In model 2 we also add NETMARRY as a proxy for the theoretical variable $\mathrm{p}$, in an attempt to separate the partial effect of $\mathrm{p}$ on TFR from the effect of all other regressors on the other component of TFR the family fertility rate $(2 n)$. This is, of course, an imprecise way of separating the relevant effects, 
since NETMARRY is a flow variable while $p$ is a stock variable. Therefore TFR cannot be expected to be proportional to NETMARRY. ${ }^{7}$

\section{Corroborations and Additional Sensitivity Tests}

1. Two-Stage Least Squares (2SLS) Estimates. In part 1 of Table 2 we rerun the regressions in model 1 of Table 1 for all key dependent variables, treating both our tax rate measure, $\mathrm{PEN}_{\mathrm{t}}$, and the level of real GDP per capital, GDPN $\mathrm{t}_{\mathrm{t}}$ as endogenous variables, whenever such treatment is justifies by Hausman's tests. To save space, we report, however, only the coefficients and elasticity estimates (in square brackets) associate with our key variable of interest - PEN. The 2SLS results strongly corroborate the results of Table 1.

2. PAYG v. Provident-Fund Systems. An important corroborative test of our model is the comparative effect of PEN in countries where social security operates as a defined-contributions “provident fund”, rather than a PAYG, defined-benefits system. In provident-fund countries, PEN represents essentially a compulsory retirement-savings rate rather than a tax. It may alter overall private savings only to the extent that the former exceeds the voluntary savings rate. But even in this case, there will be little change in private savings if individuals can borrow against their providentfund savings. Indeed, some provident funds permit using individual balances to finance health, education, and housing needs, which allows savings to adjust to its privately desired level. We thus expect PEN to exert little impact on family choices in provident-fund, relative to PAYG, countries.

Our sample includes just three countries having a government-managed provident fund (Fiji, Malaysia and Singapore). Applying Chow's test for the equality of regression coefficients in this subset relative to our PAYG subset, we reject the hypothesis of equal PEN coefficients in all regressions. ${ }^{8}$ Moreover, PEN has statistically insignificant effects on all dependent variables except MARRY when we run separate regressions for provident-funds countries (see Table 2 part 2). 
3. OECD v. Non-OECD Countries. Our theoretical simulations indicate that the elasticities of $p$ and TFR with respect to $\theta$ are higher in magnitude when the tax rate levels (PEN) are higher and the economy is in a more advanced stage of development. To test these implications empirically, we have separated our sample to OECD and non-OECD countries, since PEN is also considerably higher in the former subset: In OECD countries, average PEN is 5.65\%, while in non OECD countries it is $2.08 \%$, over the sample period. Consistent with Table 1 , the absolute elasticities of each of the endogenous variables with respect to PEN are over 8 times larger for NETMARRY and over 10 times larger for TFR in the OECD relative to the non-OECD set (see Table 2 part 3).

4. Overlapping and Non-Overlapping Periods. Tables 1 and 2 report the results of just overlapping 5-year specifications, where the dependent variables, $\overline{\mathrm{y}}_{\mathrm{t}, \mathrm{t}+4}$, and all regressors are computed over consecutive first periods $(t, t+1$, etc.). To achieve greater time-independence of our dependent variables, we also performed regressions based on non-overlapping 5-year periods (starting at $t, t+5$, etc.). This specification is disadvantaged by significant declines in the sample sizes in all regressions. Nevertheless, the results it yields are corroborative and generally consistent numerically with those of Tables 1 and 2 . We thus skip reporting them to save space.

5. Introducing Year (Trend) as an Additional Regressor. As a further sensitivity test, we introduce chronological time (year) as an additional regressor to control for spurious correlations between PEN and our dependent variables due to opposite time trends. However, per-capita GDP (GDPN), which serves as an independent regressor in all of our regressions, is itself highly timetrended. Adding a separate time trend variable can thus reduce the accuracy of the regression estimates due to multicollinearity. Nevertheless, the effect of PEN in part 4 of Table 2 remains statistically significant in all regressions. 


\section{Concluding Remarks}

The total fertility rate in the 28 OECD countries in our sample (see the legend in Table 2) has fallen over our sample period from 2.80 in 1965 to 1.74 in 1989 , and the trend is continuing: TFR reached 1.64 in 2000. The decline in the net marriage rate in the OECD set has been even more dramatic: it fell from 9.97 in 1960 to 4.86 in 1990 and to 3.17 in 2000 . These trends apply to the 29 non-OECD countries in our sample as well, albeit to a different degree: average TFR fell from 5.39 in 1965 to 2.81 in 1989 while the net marriage rate was 9.14 in 1960 and 9.48 in 1990. Our theoretical and empirical analysis indicates that the dramatic declines in key demographic variables owe largely to 2 major influences: the rise in the shadow price of quantity relative to quality of children, captured by indicators of labor market opportunities for females, and the autonomous effect of the "demographic transition" associated with the process of development. Our study indicates, however, that social security's rising tax rate, PEN, has exerted an independent and sizeable influence on these trends as well. This inference is backed up by the following set of corroborating findings:

1. Our regression and calibrated simulation analyses yield consistent qualitative, and even quantitative, estimates of the impact of social security tax rates on family formation and fertility for comparable measures of these variables. In elasticity terms, our simulations indicate that a $1 \%$ increase in PEN lowers the probability of adult marriage (p) by $.231 \%$, the family fertility rate $(\mathrm{FFR}=2 \mathrm{n})$ by $.075 \%$, and TFR by $.306 \%$ at the sample-average values of PEN. By our regression analysis, the corresponding elasticity estimates indicate that a $1 \%$ rise in PEN lowers the net marriage rate by $.369 \%$ while lowering $\mathrm{n}$ and TFR by $.119 \%$ and $.284 \%$, respectively (see table inside Fig. 1). While the elasticities for $\mathrm{p}$ and $\mathrm{n}$ are not quite comparable across our simulations and the regressions, those for TFR are comparable and quite close: .306 versus .284. 
In terms of the model's explanatory power the inference is that over the period 1965-1989 (for which we have panel data on TFR) the rise in PEN accounts for $48.1 \%$ of the actual decline in TFR (see fn. 4) according to our simulations, and for $39.2 \%$ according to our regressions. Our regression results indicate that the rise in PEN from 2.84\% in 1960 to $8.04 \%$ in 1990 explains an even larger share $-51.5 \%$ - of the actual decline in the net marriage rate (from 9.97 to 4.86 ) over the same period. Moreover, while an increase in PEN lowers the rate of marriage, it raises the rate of divorce, which is a logical derivative of the expected impact on family formation.

2. An important insight of our study is that movements in total fertility rate - the main statistic used to track fertility changes - is actually a product of two separate determinants: the fraction of the adult population forming families (p) and the within-family fertility rate $(\mathrm{FFR}=2 \mathrm{n})$. Our simulations show that the social-security-induced fall in $\mathrm{p}$ accounts for a larger share of the induced decline in TFR (75\%) than the social-security-induced fall in FFR $(25 \%)$. This is essentially because the estimated elasticity of $\mathrm{p}$ with respect to PEN (.2314) is 3 times higher than that of $\mathrm{n}(.0747)$.

3. The estimated elasticities of our demographic variables with respect to our tax rate measure are much larger in OECD, relative to non-OECD countries (as reported in Table 2). This pattern is consistent with our theoretical expectations, and it is corroborated by both our calibrated simulations and our regressions. The level of PEN in OECD countries has been significantly larger in OECD countries, rising form $2.84 \%$ in 1960 to $8.04 \%$ in 1990 , than in non-OECD countries, where it rose from a very low initial level of $0.37 \%$ in 1960 to $3.91 \%$ in 1990 , and as our analysis predicts, the adverse impact of the tax rate increases with its level, as well as with the economy's stage of development. Indeed, while in OECD countries, the rise in average PEN explains $48.1 \%$ of the actual decline in TFR between 1965 and 1989, in non-OECD countries the rise in PEN explains only 5.5\% of the actual fall in TFR (from 5.39 in 1965 to 2.81 in 1989). 
4. A similar pattern applies if we compare the projected effects of PEN in all OECD countries relative to its corresponding effects in the US, since the US had a markedly lower average tax rate over the sample period, $3.6 \%$, relative to that in the OECD countries as a whole, $5.65 \%$. In another paper (see Ehrlich and Kim, 2006) we estimate, based on calibrated simulations using US data, that a $1 \%$ change in PEN in the US over the sample period would lead to a reduction of $.0459 \%$ in $\mathrm{p}, .0442 \%$ in $\mathrm{n}$, and $.0900 \%$ in TFR, while the corresponding calibrated simulation estimates using OECD data are substantially higher: .2314, .0747, and .3059, respectively.

5. Another result that is consistent with our analysis in section I.1 is that while in definedbenefits, PAYG countries, a rise in the equilibrium tax rate has a non-trivial effect on all demographic variables, in countries where social security is structured as a provident fund a rise in PEN (representing essentially a forced savings rate) has virtually no effect on NETMARRY and TFR (see section IV.2).

Ironically, the financial vulnerability of the defined-benefits, PAYG system in both the US and other OECD countries is, at least in part, the result of the adverse incentive effects on family formation and fertility generated by the way the PAYG social security system is structured, and the financial peril in OECD countries is significantly greater than in non-OECD countries, and even in the US. The implication is that reforming the structure of social security from defined-benefits, PAYG system to fully funded provident funds or individual savings account might have significantly moderating effects on the trends in the key demographic variables we have investigated in this paper. Moreover, our study implies that alternative ways of reforming the system - for example, by raising the tax rate further to stave off future deficits could actually exacerbate the downward trends in key demographic variables, even if it could alleviate the financial burden on PAYG systems in the short run. 


\section{Appendix}

A.1 We consider a closed economy with workers of homogeneous capacity and fixed labor supplies. Workers differ, however, in some idiosyncratic attributes that affect their matching prospects, which is why in equilibrium not all form families. We limit search for a lifetime mate to take place at the start of adulthood, after which each worker winds up either "married" or "single". Search, consisting of efforts to find and bond with a mate, raises the probability of net family formation, $\mathrm{p}$, which we assume, for simplicity, to be a prerequisite for having children. We also assume that the family formation decision and subsequent household choices are based on rational expectations.

Human capital is the economy's engine of growth. Its production rule is given by:

(A.1) $\mathrm{H}_{\mathrm{t}+1}=\mathrm{A}\left(\overline{\mathrm{H}}+\mathrm{H}_{\mathrm{t}}\right) \mathrm{h}_{\mathrm{t}}$,

where the first component is raw labor, $\overline{\mathrm{H}},\left(\overline{\mathrm{H}}+\mathrm{H}_{\mathrm{t}}\right)$ represents production capacity or real earnings of an adult worker, with the wage rate, $\mathrm{w}_{\mathrm{t}}$ normalized at $1 . \mathrm{H}_{\mathrm{t}+1}$ and $\mathrm{H}_{\mathrm{t}}$ denote the human capital stocks of the generations of children and parents, respectively, and $h_{t}$ denotes the fraction of earning capacity parents invest in their children's human capital. Parents' inputs are thus essential for securing human capital formation in children.

The working young adult aims to maximize expected lifetime utility:

(A.2) $\mathrm{W}(\mathrm{t})=\Gamma\left(\lambda\left(\mathrm{p}_{\mathrm{t}}\right)\right)+\mathrm{p}_{\mathrm{t}} \mathrm{V}_{\mathrm{m}}{ }^{*}(\mathrm{t})+\left(1-\mathrm{p}_{\mathrm{t}}\right) \mathrm{V}_{\mathrm{s}}^{*}(\mathrm{t})$, where

(A.3) $\Gamma\left(\lambda\left(\mathrm{p}_{\mathrm{t}}\right)\right)=[1 /(1-\sigma)]\left\{\left[\left(1-\lambda\left(\mathrm{p}_{\mathrm{t}}\right)\right)\left(\overline{\mathrm{H}}+\mathrm{H}_{\mathrm{t}}\right)\right]^{1-\sigma}-1\right\}$.

In equation (A.2), $p_{t}$ denotes the probability of a successful mating, and $V_{m}{ }^{*}(t)$ and $V_{s}{ }^{*}(t)$ denote maximized expected lifetime utilities if a person winds up married $(\mathrm{m})$ or single $(\mathrm{s})$, respectively. Search for a mate concludes at the start of the adulthood period, and thus reflects the efforts to achieve a stable marriage as well. The term $\Gamma\left(\lambda\left(\mathrm{p}_{\mathrm{t}}\right)\right)$ denotes the cost of search in utility terms, where $\lambda\left(p_{t}\right)$ is the fraction of production capacity spent on search when the young adult is already in full possession of the earning capacity generated by parents $\left(\overline{\mathrm{H}}+\mathrm{H}_{\mathrm{t}}\right)$. The probability of a successful marriage, $p=p(\lambda)$, is a continuously increasing and concave function of $\lambda$, with $\mathrm{p}(1) \leq 1$. Its inverse function $\lambda(\mathrm{p})$ is thus increasing and convex, with $\lambda(0)=0$. The utility operator in each period is given by $\mathrm{U}(\mathrm{C})=[1 /(1-\sigma)]\left[\mathrm{C}^{1-\sigma}-1\right]$, with $\sigma>0$ to assure concavity.

The young adult thus maximizes the expected utility if married $(\mathrm{j}=\mathrm{m})$ or single $(\mathrm{j}=\mathrm{s})$ :

(A.4) $\mathrm{V}_{\mathrm{j}}^{*}(\mathrm{t})=\max [1 /(1-\sigma)]\left[\mathrm{C}_{\mathrm{j} 1}(\mathrm{t})^{1-\sigma}-1\right]+\delta \pi_{2}[1 /(1-\sigma)]\left\{\left[\mathrm{C}_{\mathrm{j} 2}(\mathrm{t}+1)^{1-\sigma}-1\right]+\left[\mathrm{C}_{\mathrm{j} 3}(\mathrm{t}+1)^{1-\sigma}-1\right]\right\}$, where

(A.5) $\mathrm{C}_{\mathrm{j} 1}(\mathrm{t})=\left(\overline{\mathrm{H}}+\mathrm{H}_{\mathrm{t}}\right)\left(1-\mathrm{vn}_{\mathrm{t}}-\mathrm{h}_{\mathrm{t}} \mathrm{n}_{\mathrm{t}}-\theta\right)$; but $\mathrm{n}_{\mathrm{t}}=0$ if $\mathrm{j}=\mathrm{s}$.

(A.6) $\mathrm{C}_{\mathrm{j} 2}(\mathrm{t}+1)=\mathrm{S}_{\mathrm{t}+1}$;

(A.7) $C_{j 3}(t+1)=B\left(\pi_{1} n_{t}\right)^{\beta}\left(\bar{H}+H_{t+1}\right)^{\alpha}$; but $C_{j 3}=0$ if $j=s$.

In equation (A.5), $\mathrm{C}_{\mathrm{j} 1}(\mathrm{t})$ and $\mathrm{n}_{\mathrm{t}}$ represent consumption and number of children of a young parent (treated as a continuous variable), assumed to be nil if the young adult is single, while $\mathrm{v}$ and $\mathrm{h}_{\mathrm{t}}$ $(\in[0,1])$ denote the unit monetary cost of raising and educating each child as fractions of earnings capacity, $\left(\overline{\mathrm{H}}+\mathrm{H}_{\mathrm{t}}\right)$. The policy variable $\theta$ is the PAYG system's tax rate on earnings, $\delta$ is an inter-temporal discount factor, and $\pi_{1}$ and $\pi_{2}$ denote probabilities of survival from childhood to adulthood and from adulthood to old age. We account for survival odds formally because they affect the demand for children and family formation, and they capture the rationale for any old- 
age insurance scheme. Since in the benchmark model social security is the only source of old-age consumption, $\mathrm{C}_{\mathrm{j} 2}(\mathrm{t}+1)$ in equation (A.6) equals the equilibrium social security benefit, $\mathrm{S}_{\mathrm{t}+1}$, in equation (A.8) below.

For married agents, the term $\mathrm{C}_{\mathrm{m} 3}(\mathrm{t}+1)=\mathrm{B}\left(\pi_{1} \mathrm{n}_{\mathrm{t}}\right)^{\beta}\left(\overline{\mathrm{H}}+\mathrm{H}_{\mathrm{t}+1}\right)^{\alpha}$ in equation (A.7), with $\alpha=1$, defines an "altruism function" in the context of our OLG setting, whereby the representative parent derives utility vicariously from the full income and number of surviving offspring, $\pi_{1} \mathrm{n}_{\mathrm{t}}{ }^{9}$. To ensure that the utility from altruistic benefits is concave with respect to $n_{t}$ and $h_{t}$, it is necessary to restrict $\beta(1-\sigma)$ and $\alpha(1-\sigma)$ to be less than 1 . To obtain interior solutions in both fertility and educational investment, it is also necessary that $\beta>\alpha=1$, otherwise quality would dominate quantity of children in a growthequilibrium steady state, since quantity always has a higher marginal cost than quality if investments in education apply equally to all children. For (childless) singles, $\mathrm{C}_{\mathrm{s} 3}(\mathrm{t}+1)$ is zero.

We assume that PAYG social security is a strictly defined-benefits system: all adults, regardless of marital status, pay the same taxes and enjoy the same defined benefits, which implies, therefore, that $\mathrm{C}_{\mathrm{s} 2}(\mathrm{t}+1)=\mathrm{C}_{\mathrm{m} 2}(\mathrm{t}+1)$. Since only children born to married agents contribute to social security, the balanced-budget, defined benefits per recipient are given by:

(A.8) $\mathrm{S}_{\mathrm{t}+1}=\mathrm{p}_{\mathrm{t}}\left(\pi_{1} / \pi_{2}\right) \mathrm{n}_{\mathrm{t}} \theta\left(\overline{\mathrm{H}}+\mathrm{H}_{\mathrm{t}+1}\right)$.

We use an overlapping-generations (OLG) framework, since this facilitates solving for family formation in a dynamic context. We recognize three overlapping generations: dependent children, working young adults, and retired old adults. To focus on demographics, we specify the choice variables in the basic model as family formation and the quantity and quality (human capital) of children. We assume that only "married" adults can have children, and do so for altruistic motives.

The dynamic solutions of this complex system have been discussed in related work (Becker et al., 1990, Ehrlich and Lui, 1991), so the following is just a brief summary. Two stable regimes can be shown to exist, which also dictate the economy's development prospects: (a) stagnant equilibrium regime where the steady state solutions allow for a relatively high fertility level but zero investment in human capital, (a Malthusian trap); (b) growth equilibrium regime, including a transitional dynamics phase, which converges on a steady state of perpetual growth. With sufficiently high values of growth-enhancing parameters $(\mathrm{A}, \mathrm{B}, \beta$, and $\mathrm{v})$, the economy can take off from a stagnant equilibrium into this growth equilibrium regime, where the marginal rate of human capital formation, $\mathrm{Ah}_{\mathrm{t}}{ }^{*}$, is sufficiently greater than 1 . Since the economies in our empirical panel all exhibit persistent positive growth, we focus henceforth on the growth equilibrium regime.

A.2 To quantify the predicted effects of social security on our key demographic variables, we calibrate the model's basic parameters using actual OECD data and consensus estimates of a few of these parameters, based on other studies. We first specify the search-for-a-mate cost function in equation (3) as $\lambda\left(p_{t}\right)=L p^{\varepsilon}$. Each of the model's "periods" is assumed to last 25 years. The average survival probabilities of the population in OECD countries from ages zero to 25 and 50 to 75 are calculated from various issues of the United Nations Demographic Yearbook, averaging 0.9663 and 0.6217 , respectively. The average OECD social security tax rate $\theta$, measured as the ratio of the pension benefits portion of social security to GDP (PEN), is 5.65\%. Based on Gruber (2006), we set the inter-temporal elasticity of substitution to be 2 , so $\sigma=0.5$. Consistent with 
many studies, we take the time preference parameter to be $1.5 \%$, thus setting our discount factor at $\delta=(1 / 1.015)^{25}$. The unit cost rate of raising children, $\mathrm{v}$, is calculated from Table 5 in Juster and Stafford (1991), summarizing the 1975-76 time-diary surveys in the US. $\mathrm{v}$ is estimated to be $3.0 \%$ of full income.

The remaining parameters, $\mathrm{A}, \beta, \varepsilon, \mathrm{L}$, and $\mathrm{B}$ are solved by combining the three first-order conditions concerning $\mathrm{h}, \mathrm{n}$, and $\mathrm{p}$ at the growth equilibrium steady state and the specified search cost function, $\lambda=\mathrm{Lp}^{\varepsilon}$, with OECD data on the ratio of consumption spending by married relative to single adults, $\mathrm{C}_{\mathrm{ml}} / \mathrm{C}_{\mathrm{sl}}=(1-\mathrm{vn}-\mathrm{hn}-\theta) /(1-\theta)$, and the average values of estimates of $\mathrm{h}, \mathrm{n}$, and $\mathrm{p}$. Over the sample period used in our regression analysis, 1960-92, average per capita GDP growth rate (Ah) was $2.92 \%$, average TFR was 2.229 , average share of married persons in the population age 15 and over was 55.78\% (calculated from the International Data Base of the US Census Bureau), and average time spent on search for a mate was $\lambda=0.1$, derived as the fraction of total time spent on social entertainment from Table 5 of Juster and Stafford (1991). $\mathrm{C}_{\mathrm{m} 1} / \mathrm{C}_{\mathrm{s} 1}$ was estimated as 0.71 which is taken from the US 1985 Consumer Expenditure Survey since the OECD data on this variable is not available to the authors. The solutions yield the following calibrated parameter values: $\mathrm{A}=19.1253, \beta=1.2794, \varepsilon=1.1524, \mathrm{~L}=0.1960$, and $\mathrm{B}=0.0786$. 
A.3 Variables used, sources, and mean values over the sample period 1960-1992.

\begin{tabular}{|c|c|c|c|}
\hline Variable & Description & $\begin{array}{c}\text { OECD } \\
\text { Mean } \\
\text { [Std. Dev.] }\end{array}$ & $\begin{array}{c}\text { Full sample } \\
\text { Mean } \\
\text { [Std. Dev.] }\end{array}$ \\
\hline PEN & Old-age, survivor, and disability-insurance portion of & 0.0565 & 0.0419 \\
\hline ("Pension") & social security benefits as a share of GDP (ILO) & {$[0.030]$} & {$[0.034]$} \\
\hline NETMARRY & Current marriage net of divorce rate (UN) & $\begin{array}{l}7.75 \\
{[2.77]}\end{array}$ & $\begin{array}{l}8.35 \\
{[2.82]}\end{array}$ \\
\hline MARRY & $\begin{array}{l}\text { Marriage rate: the annual number of marriages per } 1000 \\
\text { population age } 15 \text { and over (UN) }\end{array}$ & $\begin{array}{l}9.72 \\
{[2.32]}\end{array}$ & $\begin{array}{l}10.06 \\
{[2.53]}\end{array}$ \\
\hline DIVORCE & $\begin{array}{l}\text { Divorce rate: the annual number of divorces per } 1000 \\
\text { population age } 15 \text { and over (UN) }\end{array}$ & 2.03 & 1.69 \\
\hline TFR & $\begin{array}{l}\text { Total fertility rate: number of children born to an average } \\
\text { woman over her reproductive years (UN) }\end{array}$ & $\begin{array}{l}2.23 \\
{[0.63]}\end{array}$ & $\begin{array}{l}2.81 \\
{[1.28]}\end{array}$ \\
\hline GDPN & Real per-capita income (Summers-Heston) & $\begin{array}{l}8886 \\
{[3630]}\end{array}$ & $\begin{array}{l}6753 \\
{[3911]}\end{array}$ \\
\hline G & GDP shares of government spending (Summers-Heston) & $\begin{array}{l}14.19 \\
{[4.40]}\end{array}$ & $\begin{array}{l}14.69 \\
{[5.98]}\end{array}$ \\
\hline Pi1 & $\begin{array}{l}\text { Survival probability of the population from ages zero to } \\
\text { twenty four (UN) }\end{array}$ & $\begin{array}{l}0.97 \\
{[0.02]}\end{array}$ & $\begin{array}{c}0.95 \\
{[0.04]}\end{array}$ \\
\hline Pi2 & $\begin{array}{l}\text { Survival probability from the official qualifying age for } \\
\text { pension benefits through the following fifteen years }{ }^{2} \text { (UN) }\end{array}$ & $\begin{array}{l}0.63 \\
{[0.11]}\end{array}$ & $\begin{array}{l}0.64 \\
{[0.12]}\end{array}$ \\
\hline DSEX & $\begin{array}{l}\text { Deviation of females' population share from } 50 \text { percent in } \\
\text { absolute value (WB) }\end{array}$ & $\begin{array}{l}1.07 \\
{[1.84]}\end{array}$ & $\begin{array}{l}0.93 \\
{[1.50]}\end{array}$ \\
\hline FLFP & Female labor force participation rate (WB) & $\begin{array}{l}40.61 \\
{[11.2]}\end{array}$ & $\begin{array}{l}38.34 \\
{[12.9]}\end{array}$ \\
\hline $\mathrm{FSCH}$ & $\begin{array}{l}\text { Ratio of average schooling years for females to that for } \\
\text { males (Barro-Lee) }\end{array}$ & $\begin{array}{l}0.90 \\
{[0.10]}\end{array}$ & $\begin{array}{l}0.85 \\
{[0.16]}\end{array}$ \\
\hline M2 & Aggregate money supply (WB) & $\begin{array}{c}0.31 \\
{[0.28]}\end{array}$ & $\begin{array}{c}0.69 \\
{[11.71]}\end{array}$ \\
\hline MATURE & $\begin{array}{l}\text { Number of years elapsing from the year when the pension } \\
\text { benefits program started (SSA) }\end{array}$ & [21.1] & $\begin{array}{l}39.34 \\
{[24.1]}\end{array}$ \\
\hline POP65 & Population share of the age group 65 and & $0.11[2.73]$ & $0.09[3.97]$ \\
\hline AGE & Population share of the age group 0-14 (UN) & $0.24[0.05]$ & $0.29[0.09]$ \\
\hline SEX & Population share of the female (UN) & $0.51[0.02]$ & $0.51[0.02]$ \\
\hline INFLA & Annual inflation rate (Summers-Heston) & $4.99[2.94]$ & $5.03[3.01]$ \\
\hline PUBED & $\begin{array}{l}\text { Share of public education expenditures in GDP } \\
\text { (UNESCO) }\end{array}$ & $\begin{array}{c}5.01 \\
{[1.54]} \\
\end{array}$ & $\begin{array}{c}4.60 \\
{[1.57]} \\
\end{array}$ \\
\hline \multicolumn{4}{|c|}{$\begin{array}{l}\text { 1. Typically, the official qualifying age for pension benefits is } 55 \text { or } 60 \text { in developing countries, and } 60 \text { or } 65 \text { in } \\
\text { developed countries. } \\
\text { 2. Data sources: (ILO) International Labor Office, The Cost of Social Security, and Year Book of Labour Statistics, } \\
\text { Geneva, various issues; (UN) United Nations, Demographic Yearbook, various issues; (WB) World Bank, World } \\
\text { Development Indicators, 1998; (Barro-Lee) "International Comparisons of Educational Attainment," J. of Monetary } \\
\text { Economics, 32, 1993; (UNESCO) United Nations Educational, Scientific and Cultural Organization, Statistical } \\
\text { Yearbook, various issues; (SSA) Social Security Administration, Social Security Programs Throughout the World, } \\
\text { 1995, 97, 99; (Summers-Heston) Summers, R. and Heston, A., "The Penn World Table (Mark 5): An expanded Set } \\
\text { of International Comparisons, 1950-1988", Quarterly Journal Of Economics, 106, May 1991, updated through } 1992\end{array}$} \\
\hline
\end{tabular}




\section{REFERENCES}

Barro, Robert J. and Lee, Jongwha, "IMF Programs: Who Is Chosen and What Are the Effects?" mimeo, 2003.

Becker, Gary S. and Barro, Robert J., A reformulation of the Economic Theory of fertility", Quarterly Journal of Economics, 103, 1988, 1-25.

Becker, G.S., Murphy, K.M. and Tamura, R, "Human Capital, Fertility, and Economic Growth", Journal of Political Economy 98, 1990, S12-38.

Boldrin, Michele, De Nardi, Mariacristina and Jones, Larry E., "Fertility and Social Security," NBER Working Paper Series No. 11146, 2005.

Commission of the European Communities, The Future Evolution of Social Protection from a Long-Term Point of View: Safe and Sustainable Pensions, 2000.

Economic Policy Committee, Budgetary challenges posed by ageing populations: the impact on public spending on pensions, health and long-term care for the elderly and possible indicators of the long-term sustainability of public finances, 2001.

Ehrlich, Isaac and Kim, Jinyoung, "Social Security, Demographic Trends, and Economic Growth: Theory and Evidence From the International Experience," NBER Working Paper Series No. 11121, 2005.

Ehrlich, Isaac and Kim, Jinyoung, "Social Security and Demographic Trends: Theory and Evidence from the International Experience," working paper, 2006.

Ehrlich, Isaac and Lui, Francis T., "Intergenerational Trade, Longevity, and Economic Growth", Journal of Political Economy, 99, 1991: 1029-1059.

Ehrlich, Isaac and Lui, Francis T., "Social Security, the Family, and Economic Growth", Economic Inquiry, 1998.

Ehrlich, Isaac and Zhong, Jian-Guo, "Social Security and the Real Economy: An Inquiry into Some Neglected Issues," American Economic Review, 88 (2), 1998.

Gruber, Jonathan, "A Tax-Based Estimate of the Elasticity of Intertemporal Substitution," NBER Working Paper Series No. 11945, January 2006.

Juster, F. Thomas and Stafford Frank P., "The Allocation of Time: Empirical Findings, Behavioral Models, and Problems of Measurement", Journal of Economic Literature, 29, 1991. 


\section{ENDNOTES}

${ }^{1}$ For example, Becker and Barro (1988) use a static framework that does not allow for human capital investments and endogenous growth. Ehrlich and Lui (1998) and Ehrlich and Zhong (1998) allow for endogenous growth, but not for family formation. In most cases, backward altruism by parents towards children is the motive for having children, but Ehrlich and Lui (1998) allows also for old-age transfers from children to parents. Boldrin, De Nardi and Jones (2005), in contrast, is based on altruism of children toward parents.

${ }^{2}$ For simplicity, physical capital, formed through savings, is abstracted from this model. In a steady state it is determined by a constant fraction of income saved, and is thus expected to grow proportionately to human capital.

${ }^{3}$ We abstract from cohabitation and single parenthood on the assumption that married households are the dominant source of fertility in the population, especially over our sample period used in our empirical work.

${ }^{4}$ From Figure 1 we can calculate how much of the observed change in TFR can be explained by the effect of the increased social security tax rate, $\theta$. The actual TFR in OECD countries fell from an average of 2.8 in 1965 to 1.74 in 1989. During this period, our measure of the tax rate, $\theta$, rose from $3.78 \%$ to $7.49 \%$. At these tax rates, the projected values of TFR by our simulations are 2.4615 and 2.0132, respectively. Our model thus ascribes to the increase in the tax rate $48.1 \%=[1-(2.0132 / 2.4615)] /[1-(1.74 / 2.80)]$ of the actually observed change in TFR.

${ }^{5}$ For example, the marriage or divorce rate statistics depend on the way cohabitation is counted. Population dynamics can also be affected by different immigration policies. We lack specific data on immigration flows.

${ }^{6}$ Instrumental variables used in our first-stage regressions are: the age of the social security program since initiation (MATURE), its squared value (MATURESQ), the population share of age groups 0-14 (AGE) and 65 and over (POP65), the population share of females (SEX), the economy's inflation rate (INFLA), net export (NX), money supply (M2), and GDP share of public education expenditures (PUBED). The first five variables capture the impact of the systems' maturity, or past and prospective buildups of surpluses in the social security budgets, and the impact of retiree interest groups relative to younger age cohorts on the political willingness to raise social security benefits and taxes. INFLA, NX, M2 and PUBED are used to capture the long-term impacts of monetary, trade, and public educational policies on the GDPN level. Basmann's test indicates that these variables can indeed serve as instrumental variables in the first-stage regressions.

7 Note that in model 2 of the TFR regressions, the estimated PEN effect is -.119 in elasticity terms, while that of NETMARRY is .255. We can thus project the unconditional effect of PEN on TFR (i.e., without introducing NETMARRY as a regressor) in model 1 of the TFR regressions as $-0.119+0.255 \cdot(-0.369)=-0.213$, in elasticity terms, where -0.369 is the estimated effect of PEN on NETMARRY in model 1 of the NETMARRY regressions. This estimate $(-0.213)$ is similar to the estimated unconditional elasticity of TFR with respect to PEN in model 1 of the TFR regression (-0.284). Our results in the NETMARRY and TFR regressions are thus internally consistent.

${ }^{8}$ In these tests we use both our original set of regressors and their interaction terms with a dummy variable distinguishing provident-fund countries. F-tests were performed on the OLS regression results, since the small subsample of provident-fund countries makes it undesirable to use 2SLS.

${ }^{9}$ Both $\pi_{1}$ and $\pi_{2}$ raise the rates of return on $\mathrm{n}$ and $\mathrm{h}$ relative to the inter-temporal rate of substitution in consumption, because they raise expected psychic benefits from children, as well as material benefits from social security. Under our general Cobb-Douglas specification of the altruism function, however, $\mathrm{h}_{\mathrm{t}}$ * remains unchanged while $\mathrm{n}_{\mathrm{t}}{ }^{*}$ rises as a result of an upward shift in $\pi_{1}$ and $\pi_{2}$. The optimal family formation probability, $\mathrm{p}_{\mathrm{t}}{ }^{*}$ rises in this case, because higher $\pi_{1}$ and $\pi_{2}$ increase the gain from children, thus from forming a family. 
Table 1. Regression Results: Total Fertility, Net Marriage, Marriage and Divorce Rates

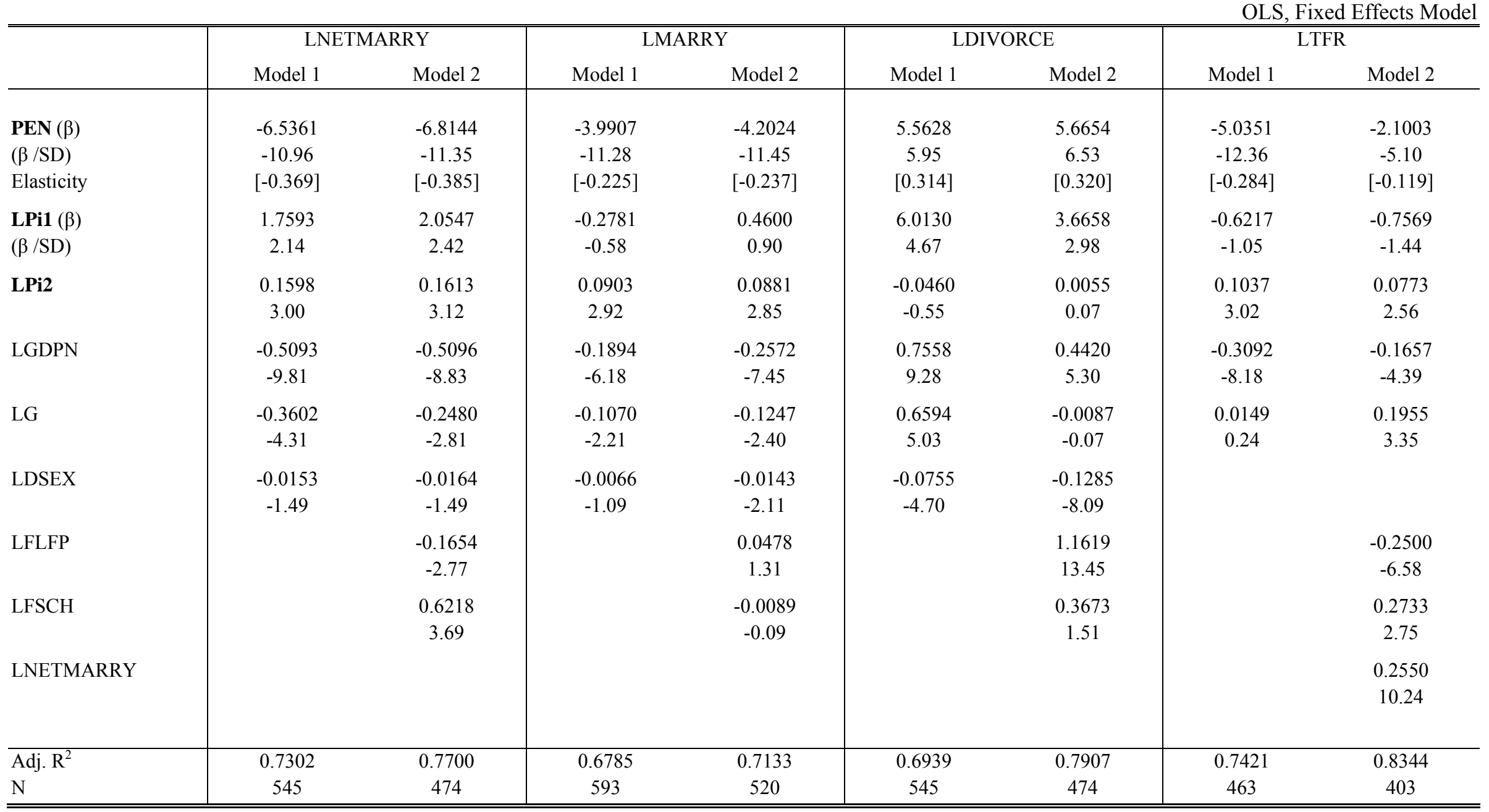

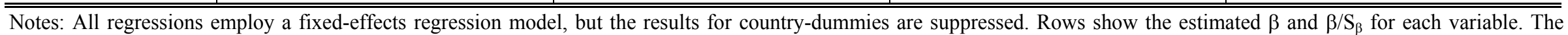

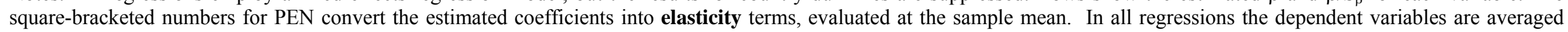
over a 5-year lead period. 
Table 2. Additional Sensitivity Tests

$\begin{array}{llll}\text { LNETMARRY LMARRY LDIVORCE } & \text { LTFR }\end{array}$

(1) Accounting for Endogeneity via the 2 Stage-Least-Square Estimation Method - OECD Sample

\begin{tabular}{lccc} 
PEN $(\beta)$ & -11.7160 & -6.8146 & 7.9342 \\
$(\beta / \mathrm{SD})$ & -8.25 & -8.00 & -3.9619 \\
Elasticity & {$[-0.662]$} & {$[-0.385]$} & -10.11 \\
\hline
\end{tabular}

(2) Comparing Provident funds v. PAYG systems -Full Sample

\section{[Provident Funds]}

PEN

$\begin{array}{lc}-0.0019 & -4.7316 \\ -0.00 & -6.33 \\ 0.000] & {[-0.102]}\end{array}$

$[-0.224]$

\begin{tabular}{|c|c|c|c|c|}
\hline & {$[0.000]$} & {$[-0.102]$} & {$[-0.005]$} & [0.009] \\
\hline \multicolumn{5}{|c|}{ [Non Provident Funds] } \\
\hline \multirow[t]{3}{*}{ PEN } & -7.8951 & -5.3907 & 5.4874 & -3.8077 \\
\hline & -16.28 & -17.50 & 7.13 & -10.97 \\
\hline & {$[-0.339]$} & {$[-0.232]$} & {$[0.236]$} & {$[-0.164]$} \\
\hline
\end{tabular}

\section{(3) OECD v. Non-OECD countries}

\section{[OECD]}

PEN

$\begin{array}{lccc}-6.5361 & -3.9907 & 5.5628 & -5.0351 \\ -10.96 & -11.28 & 5.95 & -12.36 \\ {[-0.369]} & {[-0.225]} & {[0.314]} & {[-0.284]} \\ & & & -1.3249 \\ -2.0551 & -3.0753 & 2.2228 & -2.08 \\ -3.47 & -5.92 & 1.62 & {[-0.028]} \\ {[-0.043]} & {[-0.064]} & {[0.046]} & \end{array}$

\section{(4) Entering YEAR (Trend) as an added regressor}

\begin{tabular}{|c|c|c|c|c|}
\hline PEN & $\begin{array}{c}-2.8591 \\
-4.21 \\
{[-0.162]}\end{array}$ & $\begin{array}{c}-2.8649 \\
-6.64 \\
{[-0.162]}\end{array}$ & $\begin{array}{c}3.4318 \\
3.01 \\
{[0.194]}\end{array}$ & $\begin{array}{c}-1.4464 \\
-3.61 \\
{[-0.082]}\end{array}$ \\
\hline
\end{tabular}

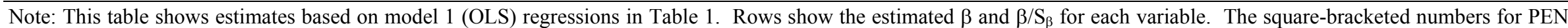

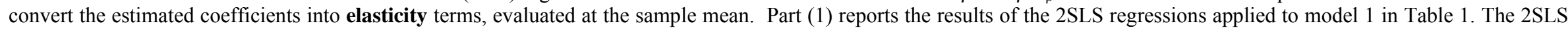

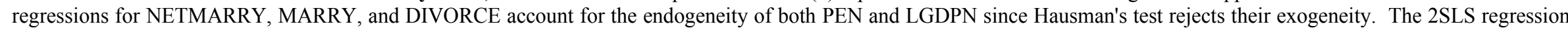

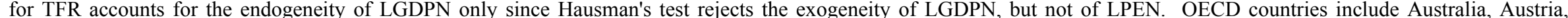

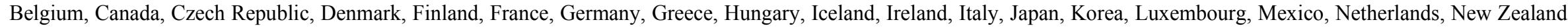

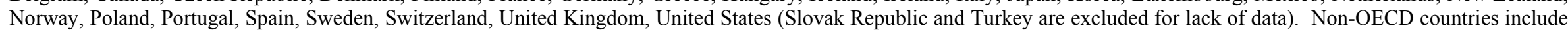

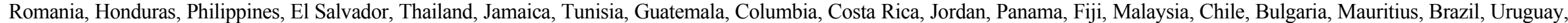
Cyprus, Yugoslavia, Barbados, Argentina, Singapore, Venezuela, Israel, Hong Kong, East Germany, and Trinidad. 
Figure 1. Simulated Steady-State Solutions for Demographic Variables as Functions of Alternative Social Security Tax Rates
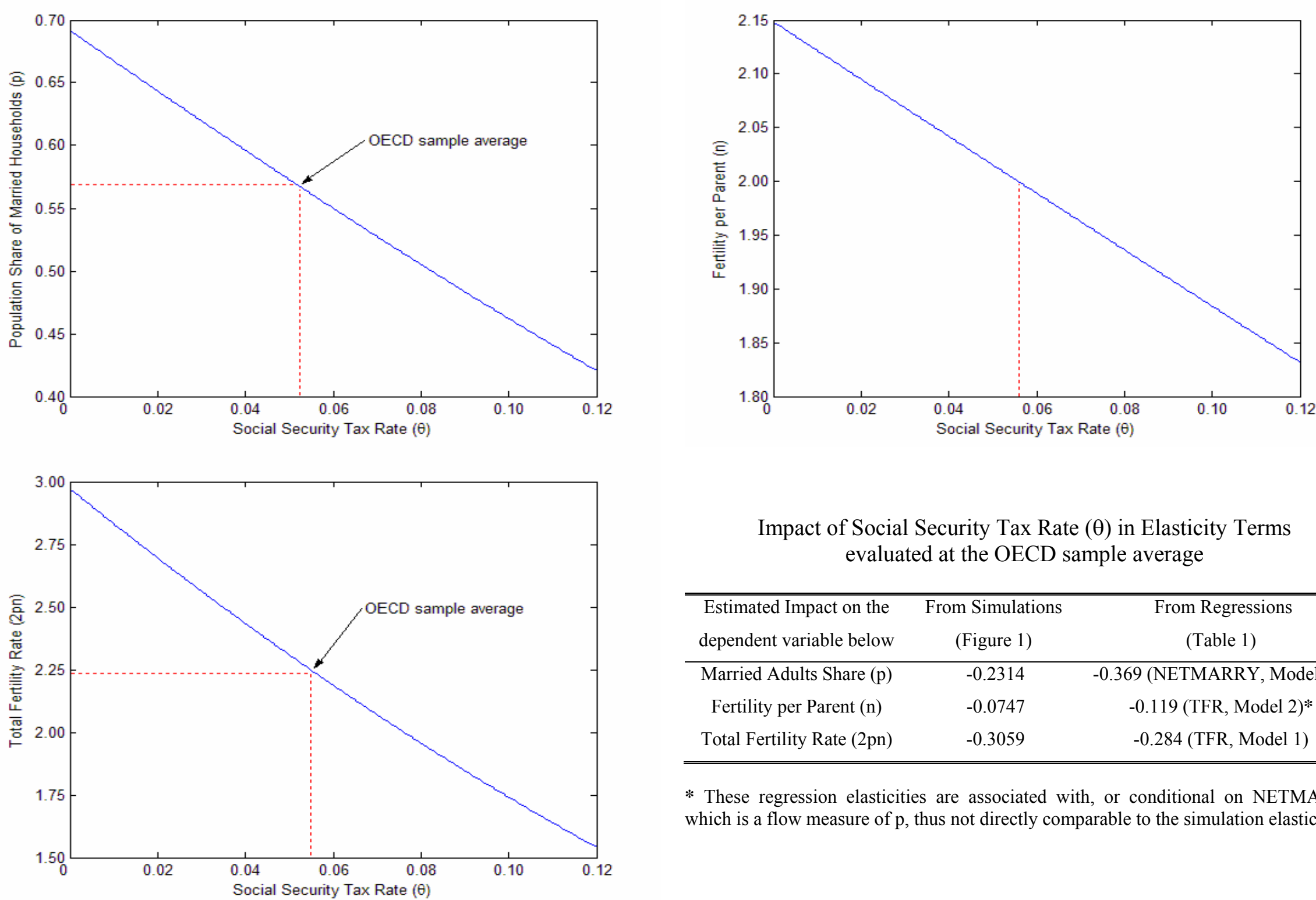

Impact of Social Security Tax Rate $(\theta)$ in Elasticity Terms evaluated at the OECD sample average

\begin{tabular}{ccc}
\hline \hline $\begin{array}{c}\text { Estimated Impact on the } \\
\text { dependent variable below }\end{array}$ & $\begin{array}{c}\text { From Simulations } \\
\text { (Figure 1) }\end{array}$ & $\begin{array}{c}\text { From Regressions } \\
(\text { Table 1) }\end{array}$ \\
\hline Married Adults Share (p) & -0.2314 & -0.369 (NETMARRY, Model 1)* \\
Fertility per Parent (n) & -0.0747 & -0.119 (TFR, Model 2)* \\
Total Fertility Rate (2pn) & -0.3059 & -0.284 (TFR, Model 1) \\
\hline \hline
\end{tabular}

* These regression elasticities are associated with, or conditional on NETMARRY, which is a flow measure of $\mathrm{p}$, thus not directly comparable to the simulation elasticities. 